\title{
Development of an early intervention to prevent long-term incapacity for work: using an online RAND/UCLA appropriateness method to obtain the views of general practitioners
}

\author{
Christine Wright ${ }^{1}$, Alice Moseley ${ }^{1,2}$, Rupatharshini Chilvers ${ }^{1}$, Laura Stabb ${ }^{3}$, John L. Campbell ${ }^{1}$ and \\ Suzanne H. Richards ${ }^{1}$ \\ ${ }^{1}$ Primary Care Research Group, Peninsula Medical School, Primary Care Research Group, Smeall Building, \\ St. Luke's Campus, Magdalen Road, Exeter, Devon EX1 2LU, UK \\ ${ }^{2}$ Department of Politics, School of Humanities \& Social Sciences, University of Exeter, Amory Building, \\ Rennes Drive, Exeter, Devon EX4 4RJ, UK \\ ${ }^{3}$ Clinical Research Methodology Unit, Peninsula Medical School, Clinical Research Methodology Unit, \\ ITTC Building, Tamar Science Park, Plymouth, Devon PL6 8BX, UK
}

\begin{abstract}
Aim: To explore the acceptability amongst general practitioners (GPs) of an early intervention to prevent long-term sickness absence from work and to identify the appropriate broad characteristics of such a service. Background: The effect of long-term sickness absence from work on individuals and society has been the subject of recent policy debate. In the United Kingdom, a number of return-to-work interventions have been piloted and plans to reform the incapacity benefit system are underway. Since GPs play a key role in the sickness certification process, their views on the appropriateness of an early return-to-work intervention were sought to help inform the development of a primary care-based model. Methods: A panel of nine GPs from eight practices in a mixed rural/urban area of the South West of England participated in a modified RAND/UCLA appropriateness method (RAM) study. Panellists completed two rounds of an online survey in which they were asked to read a summary of relevant research evidence and then rate the level of appropriateness of providing a return-to-work intervention in a series of clinical scenarios. Findings: There was general support for a return-to-work intervention. Panellists considered the intervention would be more appropriate for patients with mild-moderate rather than severe symptoms and for those with longer symptom duration. There was support for early intervention after approximately seven weeks of absence from work, but not before four weeks of absence. The return-to-work intervention was considered most appropriate for patients with repeat or recurrent patterns of sickness absence, rather than those on their first sickness absence period, and for those not already receiving specialist health input for their condition. Panellists considered that a multidisciplinary team providing a combination of biopsychosocial and vocational support would be the most appropriate model, with the service possibly being located outside of a general practice setting.
\end{abstract}

Key words: early intervention; primary care; RAND/UCLA appropriateness method; return to work; sickness absence; vocational rehabilitation

Received: 11 June 2008; accepted: 31 October 2008

Correspondence to: Dr Christine Wright, Associate Research Fellow, Peninsula Medical School, Primary Care Research Group, Smeall Building, St. Luke's Campus, Magdalen Road, Exeter, Devon EX1 2LU, UK. Email: christine.wright@pms.ac.uk

(C) 2009 Cambridge University Press 


\section{Introduction}

The progression of individuals from periods of brief absence from work on account of illness to periods of longer-term incapacity, and finally chronic incapacity for work, represents a major problem for UK employers and society. There is growing concern over how this affects labour productivity and the economy, as well as concern for the individuals involved and their families. It has been estimated that, in total, working age illhealth costs the Government over $£ 60$ billion each year (for benefits, healthcare and foregone taxes) and costs the economy as a whole over $£ 100$ billion each year (Department for Work and Pensions, 2008).

In the United Kingdom, employees can selfcertificate for absences that last between one and seven days. Doctors can issue a sickness certificate (Med3 or Med5) after seven or more consecutive days of absence, after which the employee may receive statutory sick pay (SSP) for up to 28 weeks. After an absence of more than 28 weeks, an employee who is still unfit for work may then (through Med4 certification) become eligible for incapacity benefit (IB). It has been estimated that approximately 3000 people a week move from SSP to IB (Natarajan et al., 2005) and that approximately $7 \%$ of the working population in England and Wales are claiming IB, of whom over $87 \%$ have been claiming for more than a year (NOMIS, 2007).

The general practitioner (GP) is typically the main gatekeeper of the SSP system and contributes to the decision-making process regarding eligibility for IB. One study (Sheils et al., 2004) suggests that, in each year, $12.5 \%$ of patients of working age on an average general practice list will require Med3 or Med5 certification and half of these patients may require more than one certificate, with the average duration of a sickness episode being 9.9 weeks.

The main causes of disability and sickness absence, according to general practitioner sickness certification data, employers' rankings and IB claim statistics are mental health conditions (depression, anxiety and stress), back pain or other musculoskeletal problems, and circulatory or respiratory conditions (Waddell and Burton, 2004).

A comprehensive review of research on the relationship between work and health concluded that there is strong evidence that, for most people, 'work is generally good for physical and mental health and wellbeing' (Waddell and Burton, 2006: ix) and that, wherever possible, sick and disabled people should be encouraged and supported to remain in or return to work as soon as possible - particularly those with common health problems that account for the majority of sickness absence, such as those listed above. This is consistent with recent UK Government policy in relation to health, work and wellbeing (HM Government, 2005) and a number of piloted schemes that aim to assist sick-certified individuals (receiving either SSP or IB) back into work have been evaluated (Purdon et al., 2006; Adam et al., 2008; Bewley et al., 2008).

This paper describes part of a brief scoping project conducted between September and December 2007 on behalf of the Health Work and Wellbeing Programme (Department for Work and Pensions) - http://www.workingforhealth.gov. uk/Carol-Blacks-Review/Default.aspx. The aim of the project was to inform the development of an early primary care-led intervention to support sick-listed individuals (at the Med3/Med5 stage) to return to work and avoid progression to longterm sickness absence. There were a number of elements to the project, including a literature review and preliminary interviews with a small number of GPs and occupational health specialists. This paper focuses on a consultation with a panel of GPs, using an adapted online RAND/ UCLA appropriateness method (RAM) (Fitch et al., 2001) to obtain their views on how an early return-to-work service might be delivered. The aims are two-fold: first, to investigate the appropriateness and likely broad characteristics of an as-yet unspecified early intervention; and, secondly, to illustrate the potential of the RAND/UCLA tool for testing the acceptability of new service models to practitioners in primary care.

\section{Methods}

\section{The RAND/UCLA appropriateness method}

The RAM (Fitch et al., 2001) is a well-established and internationally recognized technique, which combines a synthesis of the latest scientific evidence with the collective judgment of a panel 
of experts. The strength of the method lies in the systematic way in which it combines both professional opinion and evidence (Naylor, 1998). One use of the RAM is to obtain views on the appropriateness of medical and surgical procedures, in terms of identifying the clinical circumstances in which it would be appropriate to use the procedure or intervention in question - often as part of a process of clinical guideline development (Leape et al., 1991; Froehlich et al., 1997; Kuntz et al., 1998; Broder et al., 2000; Ciardullo et al., 2006; Prys-Picard et al., 2006). However, there has been relatively little use of RAM within the context of developing primary care interventions. A search of Medline, Web of Science, PsycInfo and ASSIA identified only eight studies that had used the RAM and involved primary care physicians; only two of these studies were UK-based (Campbell et al., 1999a; 1999b).

Typically the RAM process has three stages, namely appraisal of the existing evidence and two rounds of rating by a panel of experts. In the first round of rating, panel members independently rate a series of statements about the appropriateness of using an intervention in different clinical scenarios. Prior to the second round of the survey, the panel's median ratings from the first round are fed back to the panel members who then meet to discuss their ratings, focusing particularly on any areas of inconsistency or disagreement, before re-rating the statements independently once again. To date, the majority of published RAM studies have been conducted using paper-based methods, although more recent studies have sought to test the acceptability of electronic methods of data collection (Deshpande et al., 2005). The present study is a departure from the traditional paper-based method, employing two rounds of a web-based survey to obtain the panel members' views.

The RAM panel is typically composed of clinicians with relevant expertise (Fitch et al., 2001). The optimum panel size is between seven and 15 members. However, nine panel members has become a common rule of thumb (Fitch et al., 2001), as it is large enough to permit diversity in views, yet small enough to manage group feedback and discussion during the data collection process. Panel sizes of nine to 12 members have been found to produce results that are reproducible by second panels (Francis et al., 2007).

\section{Sampling}

We sought the views of GPs because they are the health professionals most likely to issue patients with a sickness certificate and, potentially, most likely to refer patients to a returnto-work service based in a primary care setting. Thirty-two local GPs (from 16 practices) were approached with information about the project and invited to participate in the consultation work. Follow-up telephone calls secured the initial agreement of 12 GPs, although three were subsequently unable to participate in the online survey. Our RAM panel thus represents a convenience sample of nine GPs (six male and three female), who were currently practising within eight different practices in a mixed urban and rural setting within the South West of England.

\section{Survey design and procedure}

For pragmatic reasons, we used an adapted RAM process to obtain the views of the nine general practitioners (GPs) on the panel. GPs took part in two rounds of survey ratings, conducted via an online questionnaire accessible from the study website, using a unique user name and password. Each round was open for ten days and took approximately $25 \mathrm{~min}$ to complete. Panellists could complete the survey at any time whilst the round was open and could access it on different occasions, if they were unable to complete all the items in one sitting. Unlike the traditional RAM process, we did not arrange a panel meeting prior to the second survey round for panellists to discuss their first round ratings face-to-face. However, GPs could add free-text comments to the questionnaire and a summary of all the comments made in the first round of the survey was presented to panellists in the second round. This adapted process was chosen to provide the flexibility for panellists to participate in the research at times to fit around their clinical workload and other commitments.

Prior to participating in round one of the survey, panellists were e-mailed a 12-page summary of the evidence derived from a review of the research literature. This included evidence on the epidemiology of sickness absence (eg, prevalence, average duration, common causes) and evidence regarding the relationship between health and work, and return-to-work interventions (eg, likely 
content, effectiveness, timing, intensity). Panellists were asked to consider this information and combine it with their own clinical judgment when responding to the survey items. The evidence summary could also be accessed by panellists via a link on the survey website.

The RAM method makes use of statements that share a similar stem but have varying endings. Each statement may contain a number of contrasting variables. A total of 91 statements about the proposed return-to-work service model were included in the online survey and the statements were divided into three main sections. Part A of the survey focused on the characteristics of patients for whom the intervention might be appropriate, while Part B focused on the broad characteristics of the return-to-work intervention itself. Part $\mathrm{C}$ explored team composition and the skill mix required to deliver the intervention. Statement content was based on indicators derived from the research literature and a small number of preliminary interviews with GPs and occupational health specialists. Box 1 shows the range of indicators (and their different levels) that panellists were asked to consider in each section of the survey.

In Parts A and B, panellists rated each statement with respect to appropriateness, using a 9-point scale (ranging from ' $1=$ definitely inappropriate' to ' $9=$ definitely appropriate'). In Part $\mathrm{C}$ of the survey, they were asked to rate each potential team member in terms of their necessity (ranging from ' $1=$ no relevance to sickness absence' to ' $9=$ absolute necessity for all patients'). Full definitions of the two rating scales and other terminology used in the questionnaire were accessible via the web page. At the bottom of each page, there was space for the panellists to add notes or comments to expand on their responses.

In the first round of the survey, panellists were asked to rate all the statements. In the second round, panellists viewed the same series of statements together with a reminder of their own ratings in the previous round. In addition, for each statement, they were presented with the panel's median rating, an interpretation of this (in terms of appropriateness or necessity), the range of responses and any free-text comments made. In the second round, panellists were invited to focus their attention on the highlighted statements upon which the panel had disagreed in the first round, but were able to revise any of their previous ratings in light of the new information presented. Panellists could, however, leave their previous ratings unchanged and there was no attempt to force the panel to consensus.

\section{Data analysis}

Data analysis took place at two time points after round one and after round two of the survey. For each statement, a median score was calculated, together with the range and distribution of ratings. The median panel scores were categorized into three levels - 'inappropriate/unnecessary' (median 1-3), 'uncertain' (median 4-6), or 'appropriate/ necessary' (median 7-9) (Fitch et al., 2001). Any statement where there was disagreement amongst the panel was classified as 'uncertain', regardless of the median score. Disagreement is defined as when three or more panellists' ratings fall in the lowest tertile of the scale (1-3: inappropriate/unnecessary) and three or more panellists' ratings fall in the highest tertile (7-9: appropriate/necessary), implying a polarization of views (Fitch et al., 2001).

\section{Findings}

The findings from the second round of the GP panel consultation are presented for the three sections of the survey (summarized in Box 2). At the end of the first round of the survey, the panel disagreed on 13 of the 91 statements presented; after the second round, they disagreed on only 5 of the 91 statements.

\section{Patients for whom the return-to-work intervention might be appropriate}

Panellists considered a series of clinical scenarios for the three medical conditions most commonly affecting sick-listed employees (musculoskeletal, mental health and cardio-respiratory problems). For each condition in turn, 16 scenarios were presented, which varied according to symptom severity, symptom duration, availability of specialist service input and whether the patient was requesting a first or repeat sickness certificate. The median scores and distribution of the panel's ratings for each scenario are presented in Table 1.

Panellists' responses indicated that, in general, a return-to-work intervention was viewed as appropriate across a wider range of clinical scenarios 


\section{Box 1 Survey structure}

$\begin{array}{ll}\text { Section A: Patient characteristics } & \\ \text { Rated for three medical conditions separately } & - \text { mental health, musculoskeletal and cardio-respiratory problems } \\ \text { Symptom severity } & \rightarrow \text { Mild-moderate } \\ \text { Symptom duration } & \rightarrow \text { Less than one month } \\ \text { Specialist health input available } & \rightarrow \text { More than one month } \\ \text { Number of sickness certifications } & \rightarrow \text { Not awaited/received } \\ \text { Rated for all patient groups (any condition) } & \rightarrow \text { First certification } \\ \text { Current job satisfaction } & \rightarrow \text { Lepeat/extended certification } \\ \text { Access to occupational health services } & \rightarrow \text { Moderate-high } \\ \text { Length of sickness absence period } & \rightarrow \text { With access } \\ & \rightarrow \text { one to three weeks } \\ & \rightarrow \text { four to six weeks }\end{array}$

Section B: Intervention characteristics

Team structure/type of support available Multidisciplinary team

Single healthcare professional

Prioritization of particular groups of patients $\rightarrow$ Any patient of working age

Location of the service

Appropriate referrers

Appropriate relationship between service and employer organizations $\rightarrow$ Those in active employment

$\rightarrow \quad$ Those at risk of losing their job

$\rightarrow$ Within primary health care team

$\rightarrow \quad$ Within a local Department for Work and Pensions facility

$\rightarrow$ A doctor within the NHS

$\rightarrow$ Any registered health professional within the NHS

$\rightarrow$ Any registered health professional outside the NHS

$\rightarrow$ The employer organization

$\rightarrow$ Self-referral from the patient

$\rightarrow$ Working directly together

$\rightarrow \quad$ Working indirectly together via the patient

$\rightarrow \quad$ Working completely independently $\rightarrow$ Biopsychosocial and vocational support

$\rightarrow \quad$ Vocational support only

$\rightarrow$ Biopsychosocial and vocational support

$\rightarrow \quad$ Vocational support only

Section C: Skill mix necessary to deliver the service

Clinical staff (health and social care)

$\rightarrow$ Physiotherapist

$\rightarrow$ Occupational therapist

$\rightarrow$ Clinical psychologist

$\rightarrow$ Community psychiatric nurse

$\rightarrow$ Health professional trained in specific psychological techniques

$\rightarrow$ Social worker

$\rightarrow$ Occupational health specialist

Non-clinical staff

$\rightarrow$ Return-to-work coordinator

$\rightarrow$ Representative with knowledge of social security and benefits system

$\rightarrow$ Pharmacist 


\section{Box 2 Summary of findings}

An early return-to-work intervention would be most appropriate for

- A wider set of clinical indications for patients with musculoskeletal conditions than for patients with mental health or cardio-respiratory conditions

- Patients with mild-moderate symptoms, rather than those with severe symptoms

- Those with symptoms lasting one month or longer

- Those not already receiving or awaiting specialist health care or interventions

- Those on repeat or extended sickness certification, rather than those on their first certification

- Those without access to an occupational health service

- Those who have been in receipt of a sickness certificate for seven weeks or longer (or those certified for four to six weeks, if they do not have access to an occupational health service)

It would be appropriate for the proposed return-to-work service to

- Offer a combination of biopsychosocial and vocational support, as opposed to just vocational support

- Be delivered either by a multidisciplinary team or a single health professional or specialist with access to relevant skills

- Provide priority access to services for patients receiving sickness certification over and above the general population in need of such services - particularly those at risk of losing their job

- Accept referrals from health professionals and self-referrals from patients

- Work directly with the employer organization to implement appropriate work modifications

- Include relevant input from clinical staff such as a physiotherapist, occupational health specialist, clinical psychologist and/or health professional trained in specific psychological techniques, and an occupational therapist

- Include relevant input from non-clinical staff, such as a return-to-work coordinator to assist with vocational issues and an adviser with knowledge of social security issues and the benefits system

There was uncertainty about the most appropriate location for the proposed return-to-work service

for patients with musculoskeletal problems $(8 / 16$ scenarios) than for patients with mental health (4/16 scenarios) or cardio-respiratory (3/16 scenarios) conditions.

For musculoskeletal problems, the panel agreed that the intervention was appropriate for patients experiencing either mild-moderate or severe symptoms and particularly those who were requesting a repeat or extended sickness certificate and those who had not already been referred to specialist services. The panel did not, however, believe the intervention would be appropriate for patients with severe symptoms of less than one month's duration who were requesting their first sickness certificate.

For mental health problems, the intervention was deemed most appropriate for patients with mild-moderate mental health symptoms who had not already been referred to specialist services particularly those who had experienced symptoms for more than one month or were requesting a repeat or extended sickness certificate. The intervention was, however, viewed as generally

Primary Health Care Research \& Development 2009; 10: 65-78 inappropriate for patients with severe mental health symptoms - unless these had lasted for more than one month and the patient had not already been referred to specialist services (and was requesting their first sickness certificate).

For cardio-respiratory problems, the panel's view about the appropriateness of the intervention depended again on the severity and duration of the patient's symptoms, and the presence or absence of input from specialist health services. The panel indicated that the intervention would only be appropriate for patients with symptoms lasting more than one month (particularly if they had mild-moderate symptoms), who were not already receiving specialist input.

In addition to condition-specific findings, more general patterns emerged across all three medical conditions and the intervention was generally considered more appropriate for patients who:

- were experiencing mild-moderate symptoms (9/24 scenarios) rather than severe symptoms (6/24 scenarios); 
Table 1 Appropriateness of referring patients with musculoskeletal, mental health or cardio-respiratory problems

\begin{tabular}{|c|c|c|c|c|c|c|}
\hline & \multicolumn{2}{|c|}{ Musculoskeletal problems } & \multicolumn{2}{|c|}{ Mental health problems } & \multicolumn{2}{|c|}{ Cardio-respiratory problems } \\
\hline & $\begin{array}{l}\text { All panellist } \\
\text { ratings }(n=9)\end{array}$ & $\begin{array}{l}\text { Median score/ } \\
\text { (category) }^{\mathrm{a}}\end{array}$ & $\begin{array}{l}\text { All panellist } \\
\text { ratings }(n=9)\end{array}$ & $\begin{array}{l}\text { Median score/ } \\
\text { (category) }^{\mathrm{a}}\end{array}$ & $\begin{array}{l}\text { All panellist } \\
\text { ratings }(n=9)\end{array}$ & $\begin{array}{l}\text { Median score/ } \\
\text { (category) }^{\mathrm{a}}\end{array}$ \\
\hline \multicolumn{7}{|l|}{ First certificate, mild-moderate symptoms } \\
\hline $\begin{array}{l}\text { Symptoms }<1 \text { month, has specialist health } \\
\text { input }\end{array}$ & 112246679 & $4 /(U)$ & 111223477 & $2 /(I)$ & 111233669 & $3 /(I)$ \\
\hline $\begin{array}{l}\text { Symptoms }<1 \text { month, has no specialist } \\
\text { health input }\end{array}$ & 236677789 & $7 /(A)$ & 344455679 & $5 /(U)$ & 112335789 & $3 /(U)^{c}$ \\
\hline $\begin{array}{l}\text { Symptoms }>1 \text { month, has specialist health } \\
\text { input }\end{array}$ & 134667999 & $6 /(U)$ & 345557799 & $5 /(U)$ & 133557899 & $5 /(U)^{c}$ \\
\hline $\begin{array}{l}\text { Symptoms }>1 \text { month, has no specialist } \\
\text { health input }\end{array}$ & 388899999 & $9 /(A)^{b}$ & 577779999 & $7 /(A)$ & 357889999 & $8 /(A)$ \\
\hline \multicolumn{7}{|l|}{ First certificate, severe symptoms } \\
\hline $\begin{array}{l}\text { Symptoms }<1 \text { month, has specialist health } \\
\text { input }\end{array}$ & 111234678 & $3 /(I)$ & 111112357 & $1 /(I)$ & 111233347 & $3 /(I)$ \\
\hline $\begin{array}{l}\text { Symptoms }<1 \text { month, has no specialist } \\
\text { health input }\end{array}$ & 223345689 & $4 /(U)$ & 222223459 & $2 /(I)$ & 112334689 & $3 /(I)$ \\
\hline $\begin{array}{l}\text { Symptoms }>1 \text { month, has specialist health } \\
\text { input }\end{array}$ & 145567789 & $6 /(U)$ & 245555777 & $5 /(U)$ & 134557789 & $5 /(U)$ \\
\hline $\begin{array}{l}\text { Symptoms }>1 \text { month, has no specialist } \\
\text { health input }\end{array}$ & 337788999 & $8 /(A)$ & 355677799 & $7 /(A)$ & 135669999 & $6 /(U)$ \\
\hline \multicolumn{7}{|l|}{$\begin{array}{l}\text { Repeat/extended certificate, mild-moderate } \\
\text { symptoms }\end{array}$} \\
\hline $\begin{array}{l}\text { Symptoms }<1 \text { month, has specialist health } \\
\text { input }\end{array}$ & 122557789 & $5 /(U)^{c}$ & 224445677 & $4 /(U)$ & 113444689 & $4 /(U)$ \\
\hline $\begin{array}{l}\text { Symptoms }<1 \text { month, has no specialist } \\
\text { health input }\end{array}$ & 345788899 & $8 /(A)$ & 466777899 & $7 /(A)$ & 114467789 & $6 /(U)$ \\
\hline $\begin{array}{l}\text { Symptoms }>1 \text { month, has specialist health } \\
\text { input }\end{array}$ & 356669999 & $6 /(U)$ & 455557799 & $5 /(U)$ & 336667899 & $6 /(U)$ \\
\hline $\begin{array}{l}\text { Symptoms }>1 \text { month, has no specialist } \\
\text { health input }\end{array}$ & 789999999 & $9 /(A)^{b}$ & 778999999 & $9 /(A)^{b}$ & 156889999 & $8 /(A)$ \\
\hline \multicolumn{7}{|l|}{$\begin{array}{l}\text { Repeat/extended certificate, severe } \\
\text { symptoms }\end{array}$} \\
\hline $\begin{array}{l}\text { Symptoms }<1 \text { month, has specialist health } \\
\text { input }\end{array}$ & 123456789 & $5 /(U)^{c}$ & 122223457 & $2 /(I)$ & 112344478 & $4 /(U)$ \\
\hline $\begin{array}{l}\text { Symptoms }<1 \text { month, has no specialist } \\
\text { health input }\end{array}$ & 155778899 & $7 /(A)$ & 223445569 & $4 /(U)$ & 114555789 & $5 /(U)$ \\
\hline $\begin{array}{l}\text { Symptoms }>1 \text { month, has specialist health } \\
\text { input }\end{array}$ & 456777799 & $7 /(A)$ & 245556777 & $5 /(U)$ & 145556779 & $5 /(U)$ \\
\hline $\begin{array}{l}\text { Symptoms }>1 \text { month, has no specialist } \\
\text { health input }\end{array}$ & 778999999 & $9 /(A)^{b}$ & 355567799 & $6 /(U)$ & 167778999 & $7 /(A)$ \\
\hline
\end{tabular}


Table 2 Appropriateness of referring patients receiving sickness certification for any cause to a return-to-work intervention

All panellist ratings $(n=9) \quad$ Median score Category ${ }^{a}$

\begin{tabular}{|c|c|c|c|}
\hline \multicolumn{4}{|l|}{ For patients with moderate-high perceived job satisfaction } \\
\hline In receipt of sickness certification for one to three weeks & 112344579 & 4 & (U) \\
\hline In receipt of sickness certification for four to six weeks & 336789999 & 8 & (A) \\
\hline In receipt of sickness certification for seven to 12 weeks & 567889999 & 8 & (A) \\
\hline In receipt of sickness certification for 13 or more weeks & 788999999 & $\mathbf{9}$ & $(A)^{b}$ \\
\hline \multicolumn{4}{|l|}{ With access to occupational health services } \\
\hline In receipt of sickness certification for one to three weeks & 111334556 & 3 & (I) \\
\hline In receipt of sickness certification for four to six weeks & 122445667 & 4 & (U) \\
\hline In receipt of sickness certification for seven to 12 weeks & 245577888 & 7 & (A) \\
\hline In receipt of sickness certification for 13 or more weeks & 678889999 & 8 & (A) \\
\hline \multicolumn{4}{|l|}{ For patients with low perceived job satisfaction } \\
\hline \multicolumn{4}{|l|}{ Without access to occupational health services } \\
\hline In receipt of sickness certification for one to three weeks & 113456679 & 5 & (U) \\
\hline In receipt of sickness certification for four to six weeks & 235677799 & 7 & (A) \\
\hline In receipt of sickness certification for seven to 12 weeks & 356678999 & 7 & (A) \\
\hline In receipt of sickness certification for 13 or more weeks & 567799999 & $\mathbf{9}$ & $(A)^{b}$ \\
\hline \multicolumn{4}{|l|}{ With access to occupational health services } \\
\hline In receipt of sickness certification for one to three weeks & 111355579 & 5 & (U) \\
\hline In receipt of sickness certification for four to six weeks & 334567789 & 6 & (U) \\
\hline In receipt of sickness certification for seven to 12 weeks & 555678999 & 7 & (A) \\
\hline In receipt of sickness certification for 13 or more weeks & 667788999 & 8 & (A) \\
\hline
\end{tabular}

${ }^{\text {a }}$ Categories: $\mathbf{A}=$ appropriate; $\mathrm{U}=$ uncertain; $\mathrm{I}=$ inappropriate.

${ }^{\mathrm{b}}$ Statements judged as 'definitely appropriate' (median 9).

- reported symptoms lasting at least one month (11/24 scenarios) rather than of shorter duration $(4 / 24$ scenarios);

- were not already awaiting or receiving specialist health services $(14 / 24$ scenarios) rather than those had already been referred for specialist input (1/24 scenarios);

- were requesting a repeat or extended sickness certificate (9/24 scenarios) rather than their first sickness certificate (6/24 scenarios). Indeed, there were $7 / 24$ scenarios where the panel agreed it would be inappropriate to refer patients on their first sickness certification, compared to only $1 / 24$ scenario for patients requesting a repeat/extended certificate.

Regardless of the underlying medical conditions, panellists rated the appropriateness of a further series of 16 scenarios, which varied according to the patient's perceived job satisfaction, their access to occupational health services through the workplace and the length of their sickness absence (see Table 2).

Job satisfaction: Overall, the level of the employee's job satisfaction did not appear to be an important factor when the panellists considered the appropriateness of the return-to-work intervention. The number of scenarios in which the intervention was rated as appropriate was equal for patients with low job satisfaction $(5 / 8$ scenarios) and those with moderate-high job satisfaction ( $5 / 8$ scenarios).

Access to occupational health services: The panellists' responses suggest that overall it would be more appropriate for the return-to-work intervention to target patients who did not already have access to occupational health services through their workplace (6/8 scenarios), rather than those who did have access to such a service (4/8 scenarios).

Length of sickness absence: The panel members regarded the return-to-work intervention as most suitable for patients who had been certified sick for seven weeks or longer, whether or not they had access to occupational health services. There was some uncertainty amongst the panel as to whether it would be appropriate to refer patients who had been absent from work for shorter periods. The panel indicated it might be appropriate to refer patients who had been off work for four to six weeks if they did not have 
access to occupational health services through their workplace; however, it was deemed inappropriate to refer patients in the first three weeks of their sickness absence, particularly if they already had access to occupational health input and reported moderate-high job satisfaction.

\section{Characteristics of the return-to-work intervention}

In Section B, panellists considered a range of service characteristics including the following: the structure of the service; the type of support offered; the location of the service; who could refer patients to it; which patients the service might prioritize; and how closely the service might work with employer organizations. The panel scores are presented in Table 3.

Service structure: The panel members agreed it would be appropriate for the intervention to be delivered by either a multidisciplinary team or a single health professional with appropriate skills, although a simple comparison of median scores (9 versus 7, respectively) suggests that the panel's preference was for a multidisciplinary team to deliver the service.

Type of support offered: Panellists agreed that the service should offer biopsychosocial and vocational support, rather than vocational support alone. As discussed below, this would require the service to provide access to a wide range of interventions appropriate to the individual's holistic needs.

Location of service: There was some uncertainty amongst the panel about the best location for the return-to-work service. Five GPs agreed it would be appropriate to locate it within a primary healthcare team - but three felt this would be inappropriate (and one was uncertain). On the other hand, five GPs thought it would be appropriate to locate the service within a Department

Table 3 Characteristics of the return-to-work intervention service

\begin{tabular}{|c|c|c|c|}
\hline & $\begin{array}{l}\text { All panellist } \\
\text { ratings }(n=9)\end{array}$ & $\begin{array}{l}\text { Median } \\
\text { score }\end{array}$ & Category ${ }^{a}$ \\
\hline \multicolumn{4}{|l|}{ Service structure and type of support offered } \\
\hline Multidisciplinary team providing biopsychosocial and vocational support & 577899999 & 9 & $(A)^{\mathbf{b}}$ \\
\hline Multidisciplinary team providing vocational support only & 345555568 & 5 & (U) \\
\hline $\begin{array}{l}\text { Single health professional/specialist, providing biopsychosocial and } \\
\text { vocational support }\end{array}$ & 556677778 & 7 & (A) \\
\hline Single health professional/specialist, providing vocational support only & 244455667 & 5 & (U) \\
\hline \multicolumn{4}{|l|}{ Prioritizing of access to services } \\
\hline For patients of working age (irrespective of employment status) & 666788899 & 8 & (A) \\
\hline For patients in active paid employment & 578888899 & 8 & (A) \\
\hline For patients at risk of losing their employment & 889999999 & 9 & $(A)^{b}$ \\
\hline \multicolumn{4}{|l|}{ Location of the intervention service } \\
\hline Within the primary health care team (attached to GP surgeries) & 112677899 & 7 & $(U)^{\mathrm{c}}$ \\
\hline Within a local Department for Work and Pensions Facility & 334577899 & 7 & (A) \\
\hline \multicolumn{4}{|l|}{ Referrals to the service may be received from } \\
\hline A doctor within the NHS & 889999999 & 9 & $(\mathbf{A})^{\mathbf{b}}$ \\
\hline Any registered health professional within the NHS & 788889999 & 8 & (A) \\
\hline Any registered health professional outside the NHS & 466888999 & 8 & (A) \\
\hline The employer organization (eg, human resources or manager) & 345567799 & 6 & (U) \\
\hline Self-referral from the patient & 357799999 & 9 & $(A)^{b}$ \\
\hline \multicolumn{4}{|l|}{ Relationship between early intervention service and the employer } \\
\hline Work together directly to implement appropriate work modifications & 789999999 & 9 & $(\mathbf{A})^{\mathbf{b}}$ \\
\hline $\begin{array}{l}\text { Work together indirectly through the patient to implement appropriate } \\
\text { work modifications }\end{array}$ & 123445679 & 4 & (U) \\
\hline Be completely independent of each other & 111122238 & 2 & (I) \\
\hline
\end{tabular}


Table 4 Necessary resources or skills available within the return-to-work service

\begin{tabular}{|c|c|c|c|}
\hline & $\begin{array}{l}\text { All panellist } \\
\text { ratings }(n=9)\end{array}$ & $\begin{array}{l}\text { Median } \\
\text { score }\end{array}$ & Category $^{a}$ \\
\hline Health professional specializing in occupational health & 578888899 & 8 & (N) \\
\hline Community psychiatric nurse & 445667889 & 6 & (UC) \\
\hline Physiotherapist & 778888999 & 8 & (N) \\
\hline Occupational therapist & 556677789 & 7 & (N) \\
\hline Return to work co-ordinator & 567778999 & 7 & (N) \\
\hline Clinical psychologist & 666677889 & 7 & (N) \\
\hline Health professional trained in specific psychological techniques (eg, $\mathrm{CBT}^{\mathrm{b}}$ ) & 667777789 & 7 & (N) \\
\hline Representative with knowledge of social security and benefits system & 156678889 & 7 & (N) \\
\hline Pharmacist & 122233356 & 3 & (UN) \\
\hline Social worker & 234456777 & 5 & (UC) \\
\hline
\end{tabular}

${ }^{\text {a }}$ Categories: $\mathbf{N}=$ necessary; $\mathrm{UC}=$ uncertain; $\mathrm{UN}=$ unnecessary.

${ }^{\mathrm{b}} \mathrm{CBT}=$ cognitive behavioural therapy.

for Work and Pensions (DWP) facility, but two felt this would be inappropriate (and two were uncertain). Thus, using the accepted RAM interpretation, the panel's views were sufficiently polarized to indicate disagreement on this point (Fitch et al., 2001). A simple comparison of the ratings of the individual panellists also highlights this uncertainty: four GPs indicated an overall preference for a primary care-based service, three GPs for a DWP-based service and two GPs did not demonstrate a strong preference (feeling either location would be equally appropriate).

Referrals to the service: The panel agreed that it would be appropriate for the service to receive referrals from doctors and other registered health professionals within or outside the National Health Service (NHS). In addition, they felt it would be appropriate for patients to be able to self-refer into the service. There was, however, uncertainty as to whether it would be appropriate for employers to refer workers to the service.

When asked about prioritizing access to required health and social care services for specific groups of patients, the panel agreed that it would be appropriate to prioritize those of working age (irrespective of their employment status) and particularly those who were at risk of losing their job.

Working relationship between the service and the employer organization: All of the panellists agreed that the two parties should work together directly to implement appropriate work modifications (median $=9$; 'definitely appropriate'). Indeed, it was considered inappropriate for them to work completely independently of each other and most of the panel did not consider it appropriate for the service and the employer to work together indirectly through the patient.

\section{The skill mix required to deliver the intervention}

The final section explored the range of clinical and non-clinical staff that might be required to deliver the return-to-work service. Panel scores are presented in Table 4.

From the list of potential team members provided, the panel agreed that physiotherapist and occupational health specialist input was essential. It was also thought necessary for the team to include a clinical psychologist and/or a health professional trained in specific psychological techniques (such as cognitive behavioural therapy), an occupational therapist, someone to advise on social security and benefits issues, and a return-to-work coordinator. The panel did not, however, think it would be necessary for the team to include a community psychiatric nurse, a social worker or a pharmacist.

\section{Discussion}

One aim of this study was to map out the broad characteristics of a service to deliver an as-yet unspecified intervention to assist sick-listed individuals to return to work. In general, there was support amongst the GP panel for the idea of this type of intervention, particularly for patients with musculoskeletal conditions. 
The panel's responses indicated that a returnto-work intervention might be most appropriate for patients who have experienced mild-moderate symptoms for one month or more. This suggests that panellists may be reluctant to refer patients to a return-to-work intervention immediately, perhaps preferring a 'watchful waiting' policy to see whether the patient's symptoms (and incapacity for work) resolved spontaneously without the need for a formal intervention.

The panel's view was that referrals to the service should normally be made by the seventh week of the patient's absence from work but not sooner than the fourth week of absence. This timing is in line with, for example, the current recommendations for the management of low back pain (Waddell and Burton, 2000) and evidence on the normal recovery period for the majority of patients with that condition (Clinical Standards Advisory Group, 1994; Nguyen and Randolph, 2007). The optimum timing for a return-to-work intervention is, however, dependent on the underlying condition, with panellists preferring to focus resources on patients who remain unfit for work after the usual period of recovery anticipated for their health condition, and who might be at risk of progressing to long-term sickness absence without further formal intervention.

The panel agreed that the service should offer access to relevant multidisciplinary input, combining both biopsychosocial and vocational rehabilitation. This view is consistent with the available evidence on rehabilitation for common health problems (Waddell and Burton, 2004) and suggests that any return-to-work service would need to provide holistic care tailored to the individual's needs. Whilst this study did not explore the specific nature of the therapies that should be offered, these might include help to address the health condition itself, as well as any personal or psychological factors (eg, attitudes, beliefs or behaviours) and organizational or social factors that might impede the patient's return to work. In addition, the service would need to offer support to address any vocational issues that might prevent a successful return to work (eg, through workplace assessments, recommendations for work modification, graded return to work or workstation adjustments).

Input from a number of specialties was endorsed, including physiotherapy, occupational therapy, psychological therapies (eg, cognitive behavioural therapy), occupational health or organizational interventions (eg, workplace visits or workplace adjustments), and advice/support on relevant social issues, as well as appropriate medical treatment. Our panel also agreed that a return-to-work coordinator would be a key member of the multidisciplinary team. Their role might include the facilitation of effective communication and active collaboration between the patient, employer, GP and other health or social care professionals - factors that have been identified as crucial to a successful return to work in the research literature (Waddell and Burton, 2000; 2004; Seymour and Grove, 2005; MacEachen et al., 2006).

There was, however, some uncertainty amongst the panel with regard to the best location for the return-to-work service. Whilst some felt it would be appropriate for the service to be based within a primary care setting, others felt it should be located within a Department for Work and Pensions facility. This was an unanticipated finding and one that requires further investigation. It may reflect more general concerns about the existing sickness certification system with regard to the potential for compromising the doctor-patient relationship and the need for GPs to balance their role as a patient advocate against their obligations to the benefits system and employers (Hiscock and Ritchie, 2001; Hussey et al., 2004). The preparatory interviews conducted in parallel with our panel survey (data not reported) suggest that GPs might be supportive of a return-to-work service that is based within a community-based health centre but which provides a service across several GP practices within the same geographical area (rather than being part of their own practice team). Some interviewees felt this option might be more acceptable to patients - to be referred to a team in a more familiar environment, rather than in a Department for Work and Pensions facility.

\section{Limitations of the study}

There are a number of limitations to the development work we have conducted. Firstly, the RAM panel comprised solely of GPs and, whilst the model did generally appear acceptable to our panel, we have not explored the views of 
other key groups - such as patients, other health professionals (who might be involved in sickness certification and referring patients to the service or delivering the interventions), healthcare managers and commissioners, employers and representatives from the Department for Work and Pensions. The views of these stakeholders should be considered in the further development of an early intervention to facilitate return to work.

Secondly, the consultation was based on the views of a limited number of stakeholders within a restricted (mixed urban/rural) geographical area and therefore may not provide a representative view of all GPs, and particularly those working in inner city areas. There may be scope to use the RAM process to refine the model further by consulting with a national group of experts to obtain their views.

Finally, our adapted RAM process was conducted entirely via the internet and did not incorporate an opportunity for panel members to meet to discuss their views in more depth. Thus, the data we have obtained does not allow us to understand the reasons why the panel members rated the statements as they did. This is particularly of interest with regard to areas where there was uncertainty and disagreement amongst the panel, for example, in relation to the optimum location of the return-to-work service.

\section{Potential benefits of using the RAM approach}

Whilst acknowledging there are some limitations, this study demonstrates that the RAM approach is a systematic method for assessing the acceptability of proposed interventions (eg, in terms of their likely content and structure) from the perspective of the health professionals who are likely to be influential in the successful delivery of such a service. The online survey was relatively simple to organize and coordinate within a limited timescale, with the added benefit of allowing flexibility for busy clinicians to contribute to the model development by completing the surveys at a location and time (or times) that were convenient for them.

Consistent with other qualitative methods traditionally used to explore stakeholder views to aid service development (eg, focus groups, in-depth interviews), the number of participants

Primary Health Care Research \& Development 2009; 10: 65-78 required for the RAM approach need not be large (assuming that the panel members are carefully selected and appropriate materials are provided). However, the RAM approach has a different, more quantitative focus, in that it enables the researcher to identify areas where consensus is achieved. This allows the extraction of clear, concise messages about the appropriateness or necessity of selected features of an intervention and/or its use in specific clinical scenarios, rather than providing a richer type of qualitative data that allows an exploration of the diversity and contrast that might exist amongst stakeholders' views.

\section{Future directions}

Our preliminary model provides a starting point for the further development of an early intervention to facilitate a timely return-to-work after a period of ill health. Building on our findings, and consistent with the Medical Research Council's framework for the development and evaluation of complex interventions (Medical Research Council, 2000), further work is needed with a wider range of stakeholders (eg, service users, occupational health specialists) before any such intervention is tested using empirical designs such as a randomized controlled trial methodology.

\section{Funding}

The project was supported by a grant from the Department for Work and Pensions as part of the Health Work and Wellbeing Programme.

\section{Acknowledgements}

We would like to thank the GPs who participated in the research for their interest and for making time available to put across their views. We are also grateful to our colleagues from the Peninsula Medical School who piloted the online survey and provided useful feedback on its design and usability.

\section{Ethical approval}

Not applicable. Based on the National Patient Safety Agency's four key indicators for differentiating research and non-research projects, the 
above consultation work was not categorized as research and therefore an ethics committee review was not required (National Patient Safety Agency/National Research Ethics Service, 2008). The primary aim of the project was to utilize existing knowledge to develop a service model. Survey methods were used to obtain the views of general practitioners and no intervention was being used, allocated or randomized.

\section{References}

Adam, S., Bozio, A., Emmerson, C., Greenberg, D. and Knight, G. 2008: A cost-benefit analysis of pathways to work for new and repeat incapacity benefit claimants. Norwich: Department for Work and Pensions/Her Majesty's Stationery Office.

Bewley, H., Dorsett, R. and Ratto, M. 2008: Evidence on the effect of pathways to work on existing claimants. Norwich: Department for Work and Pensions/Her Majesty's Stationery Office.

Broder, M., Kanouse, D., Mittman, B. et al. 2000: The appropriateness of recommendations of hysterectomy. Obstetrics and Gynecology 95, 199-205.

Campbell, S.M., Roland, M.O., Shekelle, P.G., Cantrill, J.A., Buetow, S.A. and Cragg, D.K. 1999a: Development of review criteria for assessing the quality of management of stable angina, adult asthma, and non-insulin dependent diabetes mellitus in general practice. Quality in Health Care 8, 6-15.

Campbell, S.M., Hann, M., Roland, M.O., Quale, J.A. and Shekelle, P.G. 1999b: The effect of panel membership and feedback ratings in a two-round Delphi survey: results of a randomised controlled trial. Medical Care 37, 964-68.

Ciardullo, A., Daghio, M. and Carapezzi, C. 2006: How to start of change a daily insulin regimen without a specialist in diabetes: effectiveness and RAND assessment of practical schemes for in-hospital or hospital-based home care services. Acta Diabetologica 43, 22-25.

Clinical Standards Advisory Group 1994: Back pain. London: HMSO.

Department for Work and Pensions 2008: Working for a healthier tomorrow: Dame Carol Black's Review of the health of Britain's working age population. London: The Stationery Office.

Deshpande, A.M., Shiffman, R.N. and Nadkarni, P.M. 2005: Metadata-driven Delphi rating on the Internet. Computer Methods and Programs in Biomedicine 77, 49-56.

Fitch, K., Bernstein, S., Aguilar, M., Burnand, B., LaCalle, J., Lazaro, P., van het Loo, M., McDonnell, J., Vader, J. and Kahan, J. 2001: The RAND/UCLA appropriateness method users' manual. Santa Monica, CA: RAND Corporation.
Francis, H., Prys-Picard, C., Fishwick, D., Stenton, C., Burge, P., Bradshaw, L., Ayres, G., Campbell, S. and Niven, R.M. 2007: Defining and investigating occupational asthma: a consensus approach. Occupational and Environmental Medicine 64, 361-65.

Froehlich, P., Pache, I., Burnand, B. et al. 1997: Underutilisation of upper gastrointestinal endoscopy. Gastroenterology 112, 690-97.

Hiscock, J. and Ritchie, J. 2001: The role of GPs in sickness certification. Leeds: Department for Work and Pensions.

HM Government. 2005: Health, work and well-being - caring for our future. London: Department for Work and Pensions, Department of Health and the Health and Safety Executive.

Hussey, S., Hoddinott, P., Wilson, P., Dowell, J. and Barbour, R. 2004: Sickness certification system in the United Kingdom: qualitative study of views of general practitioners in Scotland. British Medical Journal 328, 88.

Kuntz, K., Tsevat, J., Weinstein, M. and Goldman, L. 1998: Expert panel vs. decision-analysis recommendations for post-discharge coronary angiography after myocardial infarction. Journal of the American Medical Association 282, 2246-251.

Leape, L., Hilborne, L., Kahan, J. et al. 1991: Coronary artery bypass graft: a literature review and ratings of appropriateness and necessity. Santa Monica: RAND Corporation, Publication no. JRA-02.

MacEachen, E., Clarke, J., Franche, R.L. and Irvin, E. 2006: Systematic review of the qualitative literature on return to work after injury. Scandinavian Journal of Work Environment \& Health 32, 257-69.

Medical Research Council. 2000: A framework for development and evaluation of RCTs for complex interventions to improve health. London: Medical Research Council.

Natarajan, L., Smethurst, L., Stratford, N. and Taylor, R. 2005: The implementation of a randomised controlled trial: improving the measurement of impact in the Job Retention and Rehabilitation Pilot using a screening tool developed for the Department for Work and Pensions. In Nicaise, I., editor, Best practice in the evaluation of labour market programmes for vulnerable groups. Leuven: Hoger Instituut voor de Arbeid.

National Patient Safety Agency/National Research Ethics Service. 2008: Defining research. London: National Patient Safety Agency. Retrieved 21 October 2008 from http://www. nres.npsa.nhs.uk/rec-community/guidance/\#researchoraudit

Naylor, C. 1998: What is appropriate care? The New England Journal of Medicine 338, 1918-920.

Nguyen, T. and Randolph, D. 2007: Non-specific low back pain and return to work. American Family Physician 76, 1497-502.

NOMIS. 2007: Official labour market statistics. London: National Statistics/Department for Work and Pensions.

Prys-Picard, C., Campbell, S., Ayres, J., Miles, J. and Niven, R. 2006: Defining and investigating difficult asthma: developing quality indicators. Respiratory Medicine 100, 1254-261.

Purdon, S., Stratford, N., Taylor, R., Natarajan, L., Bell, S. and Wittenburg, D. 2006: Impacts of the job retention and

Primary Health Care Research \& Development 2009; 10: 65-78 
78 Christine Wright et al.

rehabilitation pilot. Leeds: Department for Work and Pensions.

Seymour, L. and Grove, B. 2005: Workplace interventions for people with common mental health problems: evidence review and recommendations. London: British Occupational Health Research Foundation (BOHRF).

Sheils, C., Gabbay, M. and Ford, F. 2004: Patient factors associated with duration of certified sickness absence and transition to long-term incapacity. British Journal of General Practice 54, 86-91.
Waddell, G. and Burton, A.K. 2000: Occupational Health Guidelines for the management of low back pain: evidence review and recommendations. London: Faculty of Occupational Medicine.

Waddell, G. and Burton, A.K. 2006: Is work good for your health and wellbeing? London: The Stationery Office.

Waddell, G. and Burton, A.K. 2004: Concepts of rehabilitation for the management of common health problems. London: The Stationery Office. 